\title{
A busca por um perfil competitivo e sustentável na estratégia organizacional de uma construtora cearense através do uso de ferramentas Lean
}

\author{
The search for a competitive and sustainable profile in organizational \\ strategy of a builder from Ceará through the use of Lean tools
}

\author{
Pedro Rodolfo Freitas de \\ Matos \\ rodolfreitas@gmail.com \\ Universidade de Fortaleza \\ Bruno Mota \\ bruno.mota@sippro.eng.br
}

\begin{abstract}
Resumo
O setor da construção está se tornando mais competitivo e preocupado com a redução de desperdícios e com a sustentabilidade. Com isso, aspectos de melhoria ligados à estratégia, ao planejamento e ao controle da produção podem despertar nas empresas a busca por novas tecnologias e ferramentas ligadas à construção enxuta. Realizou-se uma pesquisa construtiva referente a melhorias tecnológicas em um canteiro de obra de uma empresa construtora de Fortaleza, Ceará. Foram evidenciadas melhorias ligadas às ferramentas Lean nas estratégias competitivas e operacionais da empresa, além da diminuição de impactos ambientais, através da inovação tecnológica dessas ferramentas. Relacionou-se a influência de ferramentas Lean às melhorias na sustentabilidade, estratégia e competitividade de uma empresa da construção civil cearense.
\end{abstract}

Palavras-chave: Estratégia competitiva. Filosofia Lean. Sustentabilidade.

\begin{abstract}
The construction industry has becoming more competitive and worried about waste reduction and sustainability. Meanwhile, improvement aspects linked to strategy and manufacturing planning and control can arouse in the companies, the search for new technologies and tools linked to lean construction. Constructive Research was made for technological improvements in a construction sites of a company of Fortaleza, Ceará. Highlighted improvements by Lean Thinking into the competitive strategies and the company's operating, in addition to the reduction of environmental impact through technological innovation of these tools. Relate the expected influence of Lean tools to improve the sustainability and strategy and competitiveness of a construction company.
\end{abstract}

Keywords: Competitive Strategy, Lean Thinking, Sustainability.

\section{Introdução}

\subsection{A relação entre estratégia competitiva, estratégia de produção e alinhamento estratégico}

Estratégia define-se como sendo o caminho escolhido pela organização para o atendimento de seus objetivos. Assim, toda organização busca o alcance de determinados objetivos e, para tal fim, precisa dispor de estratégias sobre como fazêlo (CORDEIRO, 2005).

Dos conceitos amplamente difundidos de estratégia, pode-se verificar uma correlação entre os universos da estratégia competitiva (de negócios), estratégia de produção e alinhamento estratégico, mesmo havendo contribuições diferentes em cada um, como afirma Costa et al. (2011). Segundo os autores, a relação também pode ser aplicada no contexto da indústria da construção civil (ICC). Essa aplicação se faz necessária na medida em que a concorrência entre as construtoras passa a se mostrar relevante e os clientes, bem mais exigentes (ALVES, COSTA; BARROS NETO, 2009). 
$\mathrm{Na}$ indústria em geral, a concorrência e a exigência do mercado foram analisadas, dentre vários autores, por Porter (1991), através de cinco forças competitivas: (1) a ameaça de novos entrantes; (2) a intensidade da rivalidade entre os concorrentes existentes; (3) a pressão dos produtos substitutos; (4) o poder de negociação dos compradores; e (5) o poder de negociação dos fornecedores (Figura 1).

Figura 1 - Forças que dirigem a concorrência na Indústria

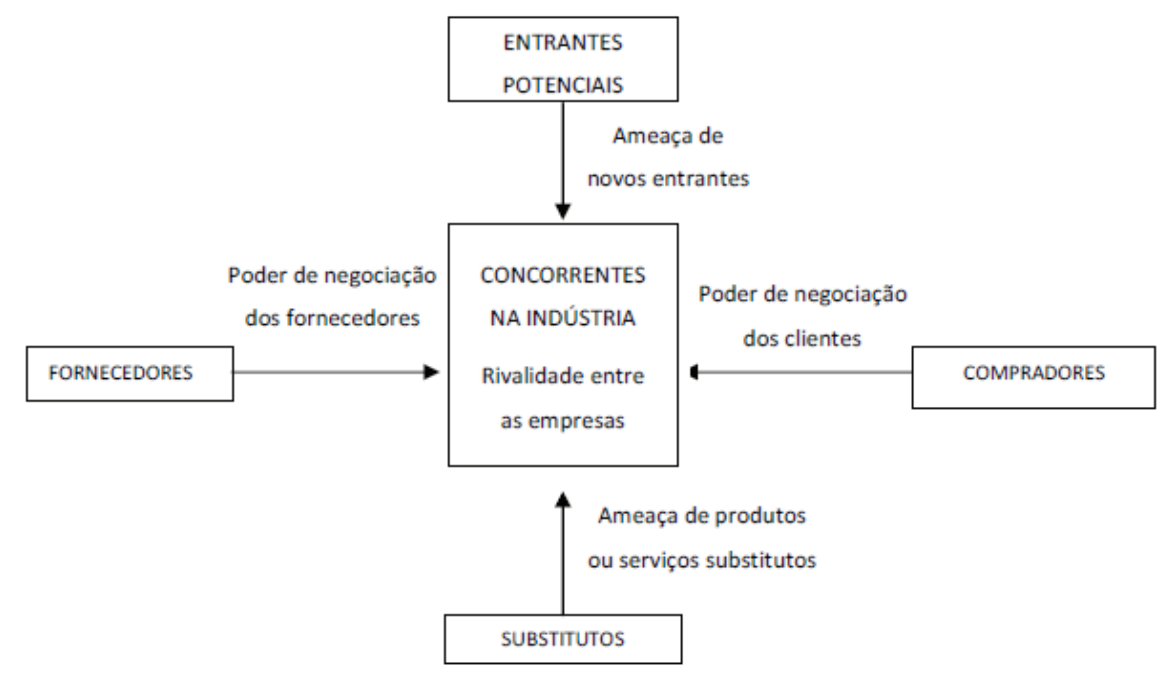

Fonte: Porter (1991) - Adaptado pelo autor.

A definição de cada representação de força, ainda segundo o autor, resume-se na Tabela 1 da seguinte forma:

Tabela 1: Análise das Forças de Porter.

\begin{tabular}{|c|c|c|}
\hline Forças & Definição & Restrição \\
\hline $\begin{array}{l}\text { Rivalidade entre } \\
\text { os concorrentes }\end{array}$ & $\begin{array}{l}\text { Uso de táticas de redução de preços, publicidade, } \\
\text { introdução de produtos e garantias. }\end{array}$ & $\begin{array}{l}\mathrm{N}^{o} \text { de concorrentes x Equilíbrio (se existem } \\
\text { poucas empresas e com os mesmos recursos, } \\
\text { a competição pode ser fatal). }\end{array}$ \\
\hline $\begin{array}{l}\text { Entrantes } \\
\text { potenciais }\end{array}$ & $\begin{array}{l}\text { Fabricação de novos produtos ou da aquisição ou } \\
\text { incorporação de uma nova unidade de negócios } \\
\text { para construir uma posição no mercado. }\end{array}$ & $\begin{array}{l}\text { Vencer as barreiras de entrada (economia } \\
\text { em escala, necessidades de capital, custos } \\
\text { de mudança, acesso a canais de distribuição, } \\
\text { desvantagem de custo). }\end{array}$ \\
\hline $\begin{array}{l}\text { Pressão de } \\
\text { substitutos }\end{array}$ & $\begin{array}{l}\text { Produtos/serviços de outra indústria, pelos } \\
\text { quais os clientes podem optar em detrimento do } \\
\text { produto da empresa. }\end{array}$ & $\begin{array}{l}\text { Quanto mais atrativa a alternativa de preço- } \\
\text { desempenho oferecida pelos substitutos, } \\
\text { mais forte será a pressão sobre os lucros da } \\
\text { indústria. }\end{array}$ \\
\hline $\begin{array}{l}\text { Poder de } \\
\text { negociação dos } \\
\text { compradores }\end{array}$ & $\begin{array}{l}\text { Quando o comprador adquire grandes volumes } \\
\text { do produto em relação ao total ou com fração } \\
\text { significativa de custo. }\end{array}$ & $\begin{array}{l}\text { Quanto maior o poder de comprador, maior a } \\
\text { ameaça em caso de perca de fidelização. }\end{array}$ \\
\hline
\end{tabular}

Fonte: PORTER (1991) - Adaptado pelo autor.

Outro ponto a ser discutido com relevância é a questão da estratégia de produção, que tem como propósito guiar a organização das operações, de forma a alinhar os recursos que irão permitir que a estratégia competitiva seja implementada efetivamente (HAYES et al., 2005). Um exemplo de estudo relacionando estratégia competitiva e estratégia de produção é o de Sun e Hong (2002), sugerindo que o alinhamento entre elas influencia positivamente o desempenho da empresa.

Sabe-se que, nos últimos anos, as decisões relativas à produção ultrapassaram uma perspectiva operacional ou de curto prazo e assumiram características mais abrangentes de abordagem estratégica. Essa mudança na postura em relação 
à função produção fez surgir um campo de pesquisa interessado em analisar o vínculo entre competitividade e produção (HAYES et al., 2005; BARROS NETO, 1999).

Em definição, o autor Greenhalgh (1991) afirma que a estratégia de produção não deve considerar apenas a tecnologia de processo, mas também as pessoas envolvidas com a produção (gerentes, supervisores e operários), o direcionamento estratégico da empresa (qual caminho a empresa deve seguir?) e o foco de atuação (quais são realmente as atividades que a empresa deve se concentrar?). O benefício é ocasionado pelo processo de determinação da estratégia de produção, formalizando a reflexão sobre como alinhar a produção e necessidades de negócio e como se diferenciar dos competidores e ganhar vantagem através da manufatura (GREENHALGH, 1991).

Verifica-se que a estratégia de produção tem como principal objetivo aumentar a competitividade da organização e, para tal, busca conformar um padrão coerente de decisões e organizar os recursos da produção, para que eles possam prover um composto adequado de características de desempenho que possibilite à organização competir eficazmente no mercado (CORRÊA; GIANESI, 1993).

É importante salientar que, em todo o mundo, as empresas buscam assegurar a estratégia como instrumento de gestão, compartilhando-a em todos os níveis da organização, gerando sinergia entre equipes, negócios, parceiros e processos. Essa tarefa conjunta é denominada, segundo Kaplan e Norton (2006), alinhamento.

Slack e Lewis (2001) definem esse alinhamento estratégico como um processo ativo que reconcilia os recursos operacionais e os requerimentos do mercado, de forma que o sucesso de uma empresa passa pelo alinhamento desta com o ambiente externo, ou seja, as decisões tomadas internamente à organização devem estar alinhadas com os aspectos externos a esta. Ainda nesse contexto, Kathuria et al. (2007) discutem o alinhamento entre o meio interno e externo de duas maneiras: dando ênfase à área de tecnologia de informação, chamado alinhamento estratégico vertical, bem como enfatizando o alinhamento entre as várias funções da organização (operações, marketing, finanças etc.), denominado alinhamento estratégico horizontal.

Em continuidade com a busca por essas adaptações estratégicas entre os meios interno e externo, o mercado da indústria da construção civil, assim como nos outros setores industriais, vem se manifestando nos últimos anos. Uma destas manifestações de caráter tecnológico é a adaptação da construção enxuta na ICC, advinda do "Lean Thinking" (Pensamento Enxuto) no setor industrial. A seguir, uma análise sobre a adaptação da Produção Enxuta para a Construção Civil e seu caráter estratégico.

\subsection{A produção enxuta na construção civil somada ao planejamento e controle produtivo (PCP) e ao alinhamento estratégico}

No segmento da construção civil de edificações, características como incerteza, variabilidade no serviço e fragmentação da indústria rodeiam os projetos e empreendimentos de muitas construtoras. Segundo Ribeiro et al. (1996), nenhuma empresa possui uma parcela de mercado significativa nem influencia fortemente o resultado da indústria. Nesse contexto, Bernardes (2001) aponta que o crescente nível de exigência por parte dos consumidores e a reduzida disponibilidade de recursos financeiros para os empreendimentos, entre outros fatores, têm estimulado as empresas a buscarem melhores níveis de desempenho, através de investimentos em gestão e tecnologia da produção.

Percebe-se, então, a necessidade de uma definição clara dos processos e das ferramentas essenciais para se alcançar eficiência e eficácia no produto final através do planejamento. De acordo com Bio (1985), o planejamento pode ser definido como o processo de desenvolvimento de alternativas e escolha de uma dentre as várias identificadas, de acordo com determinados critérios, visando à consecução de determinado objetivo futuro. De forma sistêmica, Laufer e Tucker (1987) definem planejamento como um processo subdividido em cinco etapas, conforme a Figura 2: 
Figura 2: Processo de planejamento (LAUTHER; TUCKER, 1987).

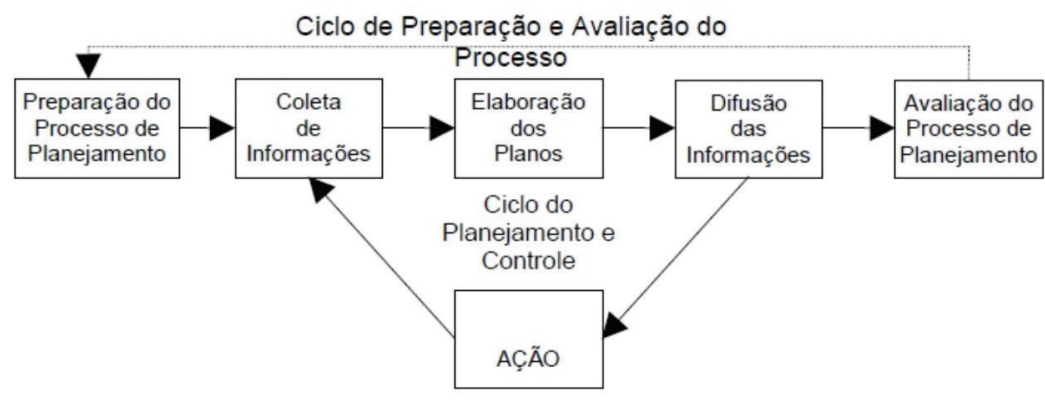

Fonte: Bernardes (2001)

A definição de cada etapa pode ser verificada a seguir (Tabela 2):

Tabela 2: Definição das etapas de planejamento.

\begin{tabular}{ll}
\hline Etapa do planejamento (Lauther e Tucker) & Definição \\
\hline \multirow{2}{*}{ Preparação do processo } & Definição de envolidos e suas responsabilidades; \\
& Níveis hierárquicos a serem adotados; \\
& Detalhamento de cada nívelde planejamento; \\
& Técnicas e ferramentas adotadas \\
Coleta de informações & Informações de clientes, projetistas, empreiteiros, poder público e \\
& consultores. \\
Elaboração dos planos & Formulação do produto do processo em função do seu tipo (plano da \\
& obra). \\
Difusão das informações & Difusão para clientes internos (setores da empresa, projetistas, \\
empreiteiros e fornecedores). & \\
Avaliação do processo & Feedback. Indicadores de desempenho para melhorias. \\
\hline
\end{tabular}

Fonte: Bernardes et al. $(1997,2001)$ - Adaptado pelo autor.

Bernardes (2001) reforça ainda o papel fundamental do processo de planejamento e controle da produção (PCP) para essas organizações, no qual inúmeros estudos comprovam que as deficiências no PCP são as causas principais para baixa produtividade do setor, altos índices de perdas e baixa qualidade de produtos finais.

Para definir o processo PCP, o autor propõe um modelo geral que interliga um conjunto de ações da empresa, percorrendo os níveis estratégico, tático e operacional, para que a partir daí se obtenha a formulação dos planejamentos de longo, médio e curto prazo do empreendimento produto (ver Figura 3). 
Figura 3: Modelo de PCP - Bernardes (2001).

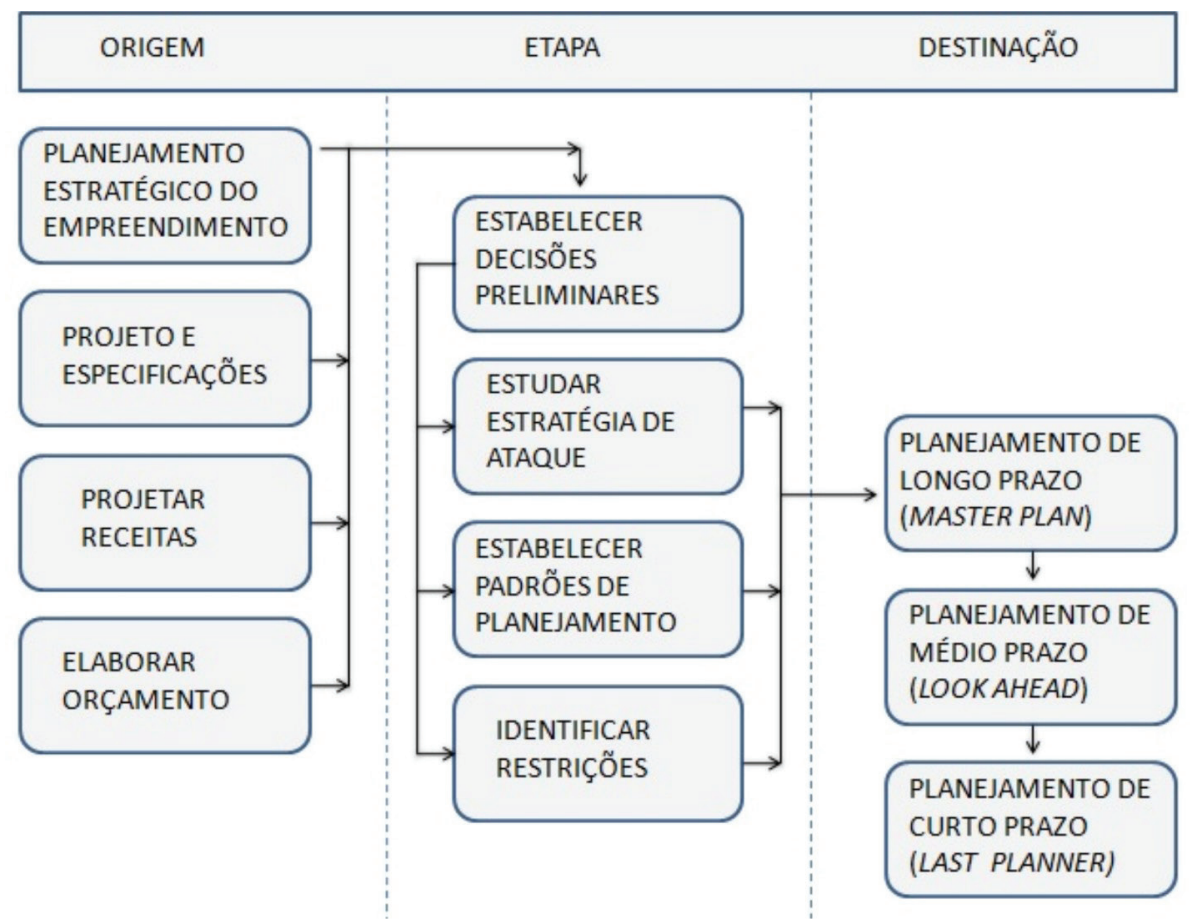

Fonte: Adaptado pelo autor.

É percebido, portanto, que esse processo requer envolvimento desde a alta direção da empresa até os respectivos gerentes de cada setor envolvido, como os gestores das obras. Como já citado, o PCP, quando mal formulado ou negligenciado, afeta negativamente a qualidade do produto além de causar improdutividade e perdas. Com isso, pode-se fazer uma relação entre o PCP e os benefícios gerados pela implantação de ferramentas da mentalidade enxuta, visto que, como consequências do seu uso, a filosofia Lean permite melhorias consideráveis na produtividade das organizações, além de redução de desperdícios.

Os princípios dessa filosofia são: especificação do valor do cliente, identificação da cadeia de valor através do fluxo de valor, implementação do fluxo continuo, uso da produção puxada e busca da perfeição. Tais princípios estão ligados a conceitos e ferramentas, como Just in time (utilizando só o tempo necessário desde o fornecimento até o cliente); nivelamento das quantidades (produção em pequenos lotes); maior autonomia dos operários, melhorando a resolução dos problemas; sinalização (Kanban indicando a produção, andon indicando os problemas de linha); e, por fim, o Kaisen, como uma ideia de melhoria contínua dos processos (WOMACK; JONES, 1998).

Na construção civil, a aplicação da filosofia iniciou-se a partir do trabalho lançado por Lauri Koskela, em 1992. Essa publicação contém onze princípios para a gestão de processos de construção. São eles:

- redução da parcela das atividades que não agregam valor: reduzindo as atividades que consomem tempo, recurso ou espaço e não contribuem para atender aos requisitos dos clientes;

- aumento do valor de saída através da consideração sistemática dos requisitos dos clientes: agregando-se valor aos produtos ao se atender os requisitos dos clientes internos e externos, os quais constituem um dos principais passos para a eficácia da produção;

- redução da variabilidade: esta tende a aumentar o tempo de ciclo, bem como a parcela de atividades que não agregam valor. Além disso, um produto uniforme é mais bem aceito pelo cliente;

- redução do tempo de ciclo: constituído por todos os tempos necessários, incluindo o tempo para inspeção, transporte, movimentação e processamento;

- simplificação através da redução do número de pessoas, partes e ligações: quanto menores são esses números, mais fáceis se tornam as atividades; 
- aumento da flexibilidade de saída: os consumidores eventualmente mudam, e é necessário condições para mudanças nas operações para satisfazer suas exigências e necessidades. A aplicação desse princípio pode ocorrer na redução do tamanho dos lotes, no uso de mão de obra polivalente, na customização do produto no tempo mais tarde possível e na utilização de processos construtivos que permitam a flexibilidade do produto sem grande ônus para a produção;

- aumento da transparência do processo: tornando mais fácil a redução de erros na produção. A remoção de obstáculos visuais, a utilização de dispositivos visuais, o emprego de indicadores de desempenho e a implementação de programas de melhoria da organização e limpeza são exemplos deste princípio;

- foco no controle do processo como um todo: tornando o processo produtivo menos suscetível ao surgimento de perdas. Pode ser realizado a partir da integração entre os diferentes níveis de planejamento;

- construção da melhoria contínua no processo: os esforços em prol da redução do desperdício e do aumento do valor do produto devem ocorrer de maneira contínua na empresa. Esse princípio é normalmente implementado através do planejamento e controle da produção;

- balanceamento de melhoria nos fluxos e nas conversões: uma está ligada à outra. Um bom fluxo necessita de menor capacidade nas atividades de conversão. A aplicação desse princípio depende muito da consciência por parte da gerência de produção de que é necessário atuar em ambas as frentes;

- realização de benchmarking: aprendizados a partir de práticas adotadas em outras empresas, tipicamente consideradas líderes num determinado segmento ou aspecto específico da produção. Deve-se procurar desenvolver os processos, e, não, copiá-los.

É possível alinhar, portanto, os princípios da mentalidade enxuta ao planejamento estratégico da empresa. Nesse caso, identifica-se uma oportunidade de melhorias quanto aos serviços, fluxo de materiais e ao próprio planejamento do empreendimento, além de melhor organização dos canteiros, almoxarifados e melhor logística dentro da obra. Esses avanços ressaltam a melhoria da produtividade da empresa como um todo, tornando-a mais competitiva e qualificada nos processos executivos (SOUSA et al., 2005).

Vale salientar que muitas empresas correm riscos implantando os princípios do Lean por não saberem se é uma prioridade estratégica. A estratégia competitiva varia de acordo com os concorrentes e clientes. Logo, se a empresa tem interesse em implantar essa nova filosofia, devem-se analisar, de acordo com o mercado, quais deles devem ser realmente introduzidos, evitando incoerências estratégicas que afetem o bom desempenho do Lean. A despreocupação em definir claramente os objetivos estratégicos, bem como a falta de planejamento levam a um não alinhamento estratégico, comprometendo a implantação da filosofia (BARROS NETO et al., 2008).

Outro ponto importante a se verificar no item seguinte, em conformidade ao que se analisou até o presente momento, é a busca por uma postura sustentável, visando uma correlação que se percebe hoje no mercado em que ser competitivo requer uma postura socioambiental dessas empresas. Da mesma forma, verificar-se-á também uma relação dessa postura com as ferramentas da construção enxuta, no sentido de evitar desperdícios de custo, geração de resíduos e impactos ambientais.

\subsection{A sustentabilidade alinhada à estratégia $e$ às novas tecnologias Lean}

A Indústria da Construção Civil vem lentamente absorvendo conceitos e políticas da gestão ambiental, voltando-se às melhores técnicas, ao cumprimento da legislação e a uma correta alocação de recursos, além de investir em pesquisa de novas tecnologias e produtos não poluentes (MOREIRA; SOARES et al., 2009). A relevância dessas ações está no fato de a indústria da construção civil ser uma das mais poluidoras, por gerar desperdício durante seu ciclo de vida (HORVATH, 2004). Logo, como já verificado nos itens anteriores, a implantação de ferramentas Lean pode garantir vantagem competitiva para empresas da construção (LEWIS, 2000).

Com relação à sustentabilidade, desde 1987, a ONU, por meio da Comissão Mundial sobre o Meio Ambiente e Desenvolvimento das Nações Unidas e do Relatório Brundtland, difundiu o termo pelo mundo baseando-se nas chamadas triple botton line (três dimensões relacionadas - ambiental, social e econômica), devendo satisfazer as necessidades da, então, atual geração, bem como das gerações futuras (WCED, 1987; ALMEIDA, 2002). Desse contexto, Kibert (2007) reforça os sete princípios necessários para a chamada construção verde: reduzir, reutilizar e reciclar o consumo de recursos, proteger a natureza, eliminar produtos tóxicos, aplicar a análise do custo do ciclo de vida e o foco na qualidade. 
Diante dos dois conceitos, deve-se entender que a adoção das práticas Lean e sustentável depende da visão estratégica do gestor de cada organização. Existem empresas que adotam exclusivamente a construção enxuta (LC) ou focam somente as práticas sustentáveis. Da mesma forma, existem as que não buscam de forma alguma as duas práticas, enquanto outras buscam adotar simultaneamente os dois princípios (Lean e sustentabilidade) em projetos de construção, gerando efeitos positivos na arquitetura, engenharia e construção (YANG et al., 2010; MAO, ZHANG, 2008; GUTIÉRREZ, 2007; KOHLER, LÜTZKENDORF, 2002).

Para perceber o nível de aplicação da mentalidade enxuta e da sustentabilidade em empresas e as possíveis interações entre os dois, podem-se utilizar modelos de mensuração, mesmo diante da dificuldade de verificação a aplicação destas filosofias (OLIVEIRA et al., 2010; BELLEN, 2006). O fato é que ambas podem ser relacionadas na medida em que possuírem objetivos em comum. Bae e Kim (2007) afirmam que o LC interfere na sustentabilidade nas seguintes perspectivas: econômica, devido à economia de recursos; social, por permitir saúde, segurança, comunicação e lealdade entre funcionários; e ambiental, pela eliminação de desperdícios e preservação de recursos.

Na mesma linha, trabalhos como o de Campos et al. (2012), testaram e verificaram que a aplicação do Lean Construction, por si só, contribui para a maturidade sustentável de uma empresa, assim como a aplicação de procedimentos sustentáveis torna a obra mais Lean. Para tanto, foram aplicadas duas ferramentas de análise: a Rapid Lean ConstructionQuality Rating Model (LCR), proposta por Hofacker (2008) para avaliação do grau de aplicação Lean, e a proposta por Farias Filho et al. (2009) para a avaliação do grau de sustentabilidade. Os autores avaliaram empresas do mercado local e mostraram similaridades entre as duas ferramentas de avaliação tais como: busca pela qualidade e melhoria contínua, redução de desperdícios e melhoria no fluxo de informações entre funcionários e gestores.

Percebe-se, portanto, uma relação positiva no alinhamento entre as estratégias competitiva e produtiva, somando-se a elas a utilização de ferramentas Lean e o comportamento sustentável.

\section{Objetivo}

O presente artigo tem como objetivo analisar técnicas de gerenciamento aplicadas em uma empresa de construção civil, identificando fatores que auxiliaram na eficiência de resultados estratégicos e operacionais. Com isso, seguem os seguintes objetivos específicos: 1) identificar em diferentes níveis da empresa, ferramentas de gestão (planejamento e controle, gestão a vista, mapeamento da produção) relacionadas à "construção enxuta" (lean construction); 2) comparar a execução de um serviço tradicional (revestimento externo de fachada) e sua mudança para a aplicação mecanizada (reboco projetado), analisando: tempo, continuidade de fluxos, logística de canteiro, produção puxada e geração de resíduos; 3) verificar a sustentabilidade e os aspectos positivos do Lean após aplicação de novas ferramentas de gestão e operação.

\section{Metodologia}

$\mathrm{O}$ artigo trata do alinhamento entre estratégia competitiva, estratégia de produção, construção enxuta e sustentabilidade, verificando o quanto as práticas Lean podem traçar novos caminhos do ponto de vista produtivo e sustentável das organizações.

A pesquisa foi adaptada, por um período, às rotinas de trabalho do pesquisador, que no caso era também um dos engenheiros residentes, e do engenheiro diretor de obras, em suas visitas ao canteiro de obras em questão. As estratégias escolhidas foram a pesquisa construtiva e a abordagem qualitativa, através de uma investigação empírica de um fenômeno contemporâneo dentro do seu contexto da vida real (YIN, 1994). Sobre a primeira, sabe-se que o construtivismo, em sua essência, consiste no envolvimento ativo entre o aprendiz (no caso, o pesquisador) e o experimento, ressaltando-se a importância dessa interação e do entendimento da ciência enquanto criação humana (OGBORN, 1997). Além disso, o estudo em questão tem o caráter exploratório, pois é feito em ambiente real, com muitas variáveis (FLYNN et al, 1990).

\subsection{Descrição da empresa e do empreendimento}

A construtora, aqui denominada Empresa A, é uma empresa de Fortaleza/CE, com empreendimentos residenciais e comerciais de alto padrão, sendo relativamente nova, com 12 anos de mercado, certificada pela ISO 9001. A obra referenciada neste trabalho consiste em um empreendimento residencial com oito blocos de quatro andares, totalizando 180 apartamentos, além de um bloco restaurante e um bloco de lazer. A área total do terreno é de $16.498 \mathrm{~m}^{2}$. 
Figura 4: Planta baixa do empreendimento.

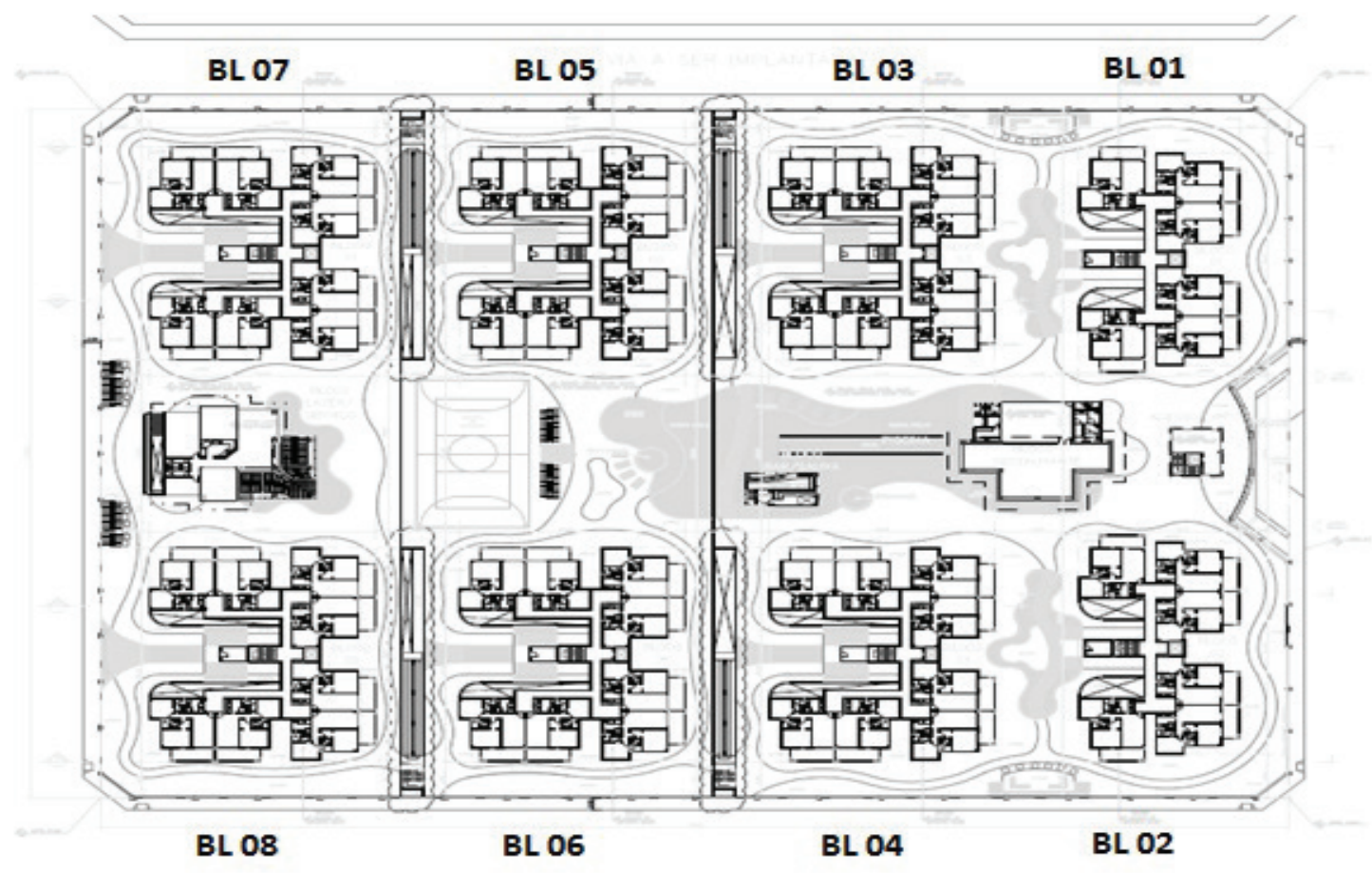

Fonte: Autor.

A partir de uma análise tecnológica e um diagnóstico ocorrido entre os meses de março de 2013 e março de 2014 junto à diretoria da Empresa $\mathrm{A}$ e à equipe técnica da obra em questão, procurou-se ter uma visão geral do problema. Para isso, usou-se como fonte de evidência esta análise, na qual foram gerados relatórios fotográficos e descritivos mensais que verificaram o comportamento antes e depois das ferramentas e melhorias aplicadas. Para tanto, ressalta-se que o autor deste artigo fez parte da equipe técnica da referida obra como engenheiro de planejamento.

\subsection{Melhorias analisadas x Principais responsáveis envolvidos}

Para tais mudanças e melhorias aplicadas, a Empresa A adotou uma sistemática de processo durante o período de diagnóstico, que pode ser verificada nas Tabelas 3 e 4:

Tabela 3: Alteração de recursos na obra.

\begin{tabular}{|c|c|}
\hline Antes do diagnóstico & Durante e depois do diagnóstico \\
\hline $\begin{array}{l}\text { Equipe da obra: } \\
\text { - } 1 \text { engenheiro residente. } \\
\text { - } 1 \text { estagiário de engenharia. } \\
\text { - } 1 \text { técnico em edificações. } \\
\text { - } 1 \text { mestre. } \\
\text { - } 3 \text { encarregados. } \\
\text { - } 1 \text { almoxarife. }\end{array}$ & $\begin{array}{l}\text { Equipe de } \mathbf{P C P} \text { da obra: } \\
\text { - } 1 \text { engenheiro de produção (antes como residente). } \\
\text { - } 1 \text { engenheiro de planejamento (acrescido). } \\
\left.\text { - } 2 \text { estagiários de engenharia (acrescido o } 2^{\circ}\right) \text {. } \\
\text { - } 1 \text { técnico em edificações (pré-existente). } \\
\text { - } 1 \text { mestre (pré-existente). } \\
\text { - } 3 \text { encarregados (pré-existentes). } \\
\text { - } 1 \text { almoxarife (pré-existente). }\end{array}$ \\
\hline $\begin{array}{l}\text { Confecção de argamassas internas e } \\
\text { externas em centrais de argamassa, de } \\
\text { forma "empurrada". }\end{array}$ & $\begin{array}{l}\text { - Aquisição de sistema e consultoria de uma empresa especializada em } \\
\text { tecnologia de projeção de argamassa para revestimentos de fachada. } \\
\text { - Kanban para argamassas internas (produção "puxada"). }\end{array}$ \\
\hline
\end{tabular}

Fonte: Autor. 
Tabela 4: Ferramentas aplicadas x Principais envolvidos.

\begin{tabular}{lccc}
\hline Ferramentas e melhorias analisadas & $\begin{array}{c}\text { Diretoria de } \\
\text { obras }\end{array}$ & $\begin{array}{c}\text { Equipe de } \\
\text { PCP na obra }\end{array}$ & $\begin{array}{c}\text { Empresa de projeção } \\
\text { de argamassa }\end{array}$ \\
\hline Aplicação de planejamento de longo, médio e curto prazo & $\mathrm{X}$ & $\mathrm{X}$ & \\
na obra & $\mathrm{X}$ & $\mathrm{X}$ & \\
Aplicação da análise de suprimentos e contratações & & $\mathrm{X}$ & \\
Aplicação de gestão à vista & $\mathrm{X}$ & $\mathrm{X}$ & $\mathrm{X}$ \\
Verificação da melhoria logística na execução de reboco & $\mathrm{X}$ & $\mathrm{X}$ & \\
externo manual x projetado & $\mathrm{X}$ & $\mathrm{X}$ & $\mathrm{X}$ \\
Aplicação do Kanban para argamassas internas & & \\
Redução de impactos ambientais & & \\
\hline
\end{tabular}

Fonte: Autor.

Foi feita uma análise comparativa das atividades, buscando resultados obtidos a partir das práticas da construção enxuta, bem como pontos fortes e os pontos fracos a serem melhorados em cada uma destas. A partir de todo esse processo de consolidação, apresentar-se-ão recomendações aos aspectos estratégicos relacionados à implantação da Lean Construction, bem como seus impactos positivos em relação ao comportamento socioambiental da empresa.

\section{Resultados e discussão}

Apesar de a filosofia Lean ainda não estar totalmente formalizada em sua estratégia, a iniciativa da empresa, através da diretoria e da equipe técnica durante o período de aplicação dos novos recursos e ferramentas, foi positiva para alguns aspectos relacionados à filosofia, havendo uma familiarização com os processos e suas características.

\subsection{Identificação de ferramentas Lean em níveis estratégicos, táticos e operacionais}

Na pesquisa de campo realizada com a diretoria de obras e a equipe técnica da obra em questão, observou-se, através da formulação da equipe de planejamento e controle de produção, um alinhamento entre a estratégia de produção da empresa e a aplicação de ferramentas relacionadas à Construção Enxuta, segundo Koskela (1992), gerando as seguintes melhorias:

1) maior flexibilidade/valor de saída (foco no cliente): clientes de apartamentos residenciais podem personalizálos, seguindo algumas regras estabelecidas pela construtora, relacionadas a aspectos financeiros e técnicos;

2) redução da variabilidade (padronização de processos): a empresa possui um padrão em suas construções, similares para todos os empreendimentos. Também está iniciando o conceito de padronização de canteiros (identificações, acessos, logomarcas, acabamentos);

3) benchmarking: a empresa realiza visitas a outras empresas para discussão e aprimoramento de novos processos. Também foi observada a disseminação de ferramentas aplicadas pela equipe de planejamento e controle produtivo da obra para as demais através de benchmarking interno;

4) transparência no processo: adaptação do planejamento com ferramentas para longo, médio e curto prazo, aplicação da linha de balanço (Figura 5), análise de restrições a médio prazo e acompanhamento diário de serviços críticos, gestão à vista (Figura 6) e análise de suprimentos e contratações. 
Figura 5: Aplicação da linha de balanço na obra.

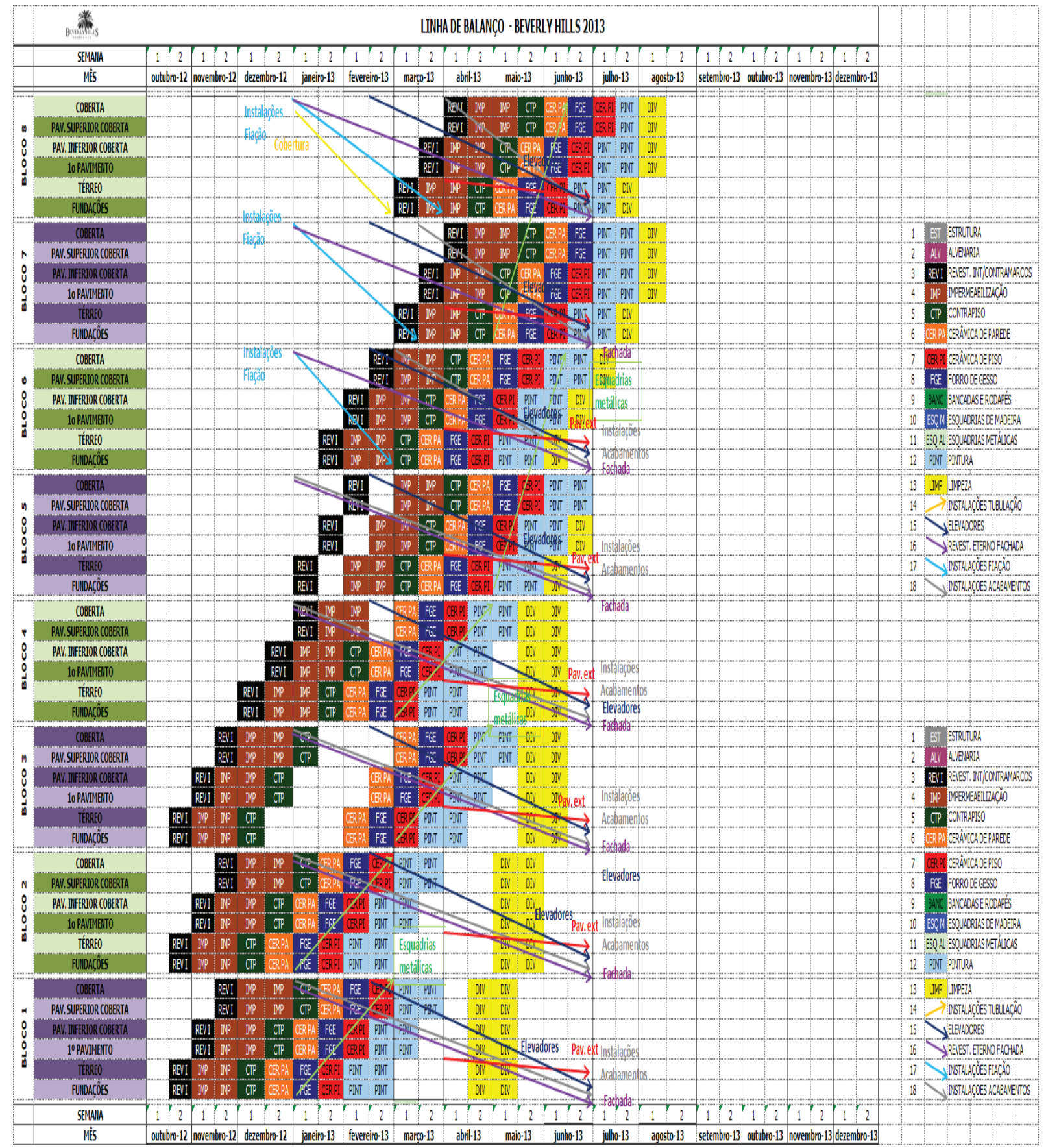

Fonte: Empresa A. 
Figura 6: Gestão à vista (a - linha de balanço; b - médio prazo; c - curto prazo)

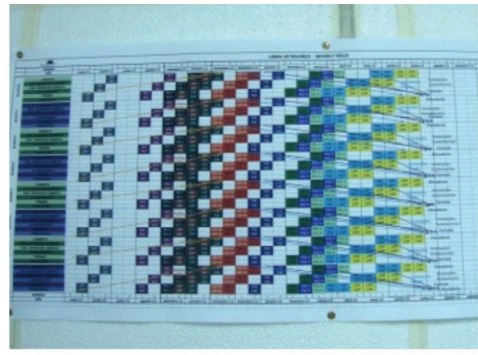

(a)

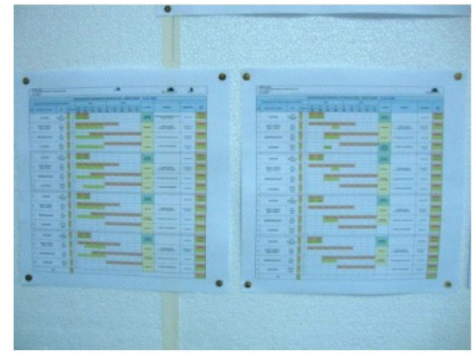

(b)

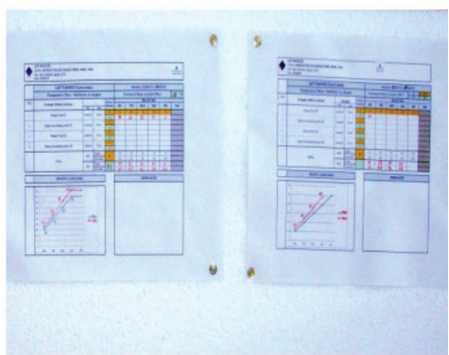

(c)

Fonte: Autor.

5) redução de tempo de ciclo: aplicação de um quadro gerenciador Kanban na central de argamassa para os traços de reboco interno e contrapisos dos 8 blocos de apartamentos (Figura 7);

Figura 7: Kanban de produção na obra (à esquerda, o Quadro Geral; à direita, o cartão Kanban).
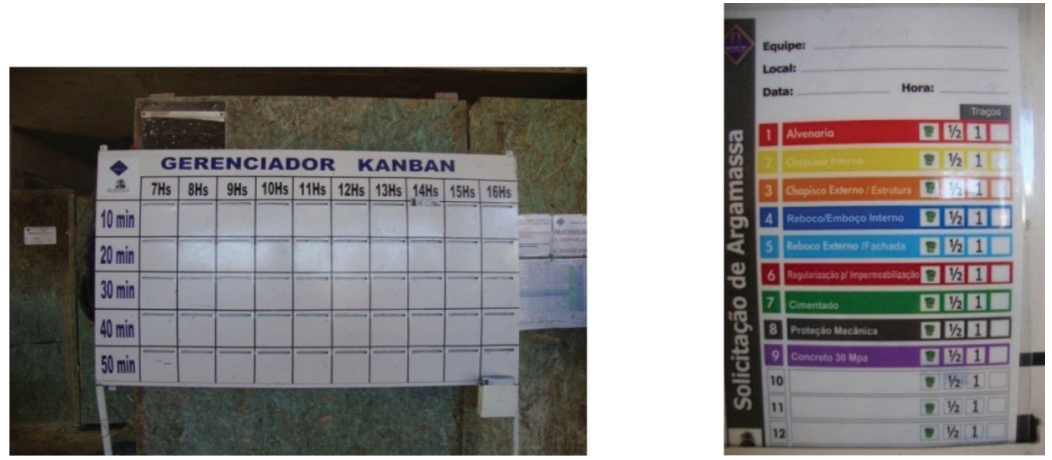

Fonte: Empresa A.

6) redução de parcelas de atividade que não agregam valor: verificou-se que a aplicação do novo método de execução de chapisco e reboco externo com máquinas de projeção eliminaram etapas como transporte horizontal e vertical, reduzindo tempo, custo e mão de obra (ver item 4.2);

7) melhoria contínua no processo: aplicação do planejamento e controle produtivo na obra além de reuniões semanais com equipe técnica da obra e terceirizados (avaliação de metas e retroalimentação).

4.2 Comparativo do serviço de revestimento externo (chapisco e reboco) manual x projeção mecanizada

Outro ponto de melhoria evidenciado foi a mudança de execução de revestimentos de fachada que passou de manual para projeção de forma mecanizada. Como visto no item 3.1, a obra possui oito blocos de quatro pavimentos e área total do terreno de $16.498 \mathrm{~m}^{2}$. O revestimento externo (chapisco e reboco) vinha sendo feito de forma manual com logística bastante complexa, tendo em vista o terreno possuir três níveis. A Figura 8 resume como funcionava, com duas centrais de argamassas, transporte horizontal e vertical envolvendo equipes de serventes, giricas e guinchos foguetes instalados em cada bloco residencial. O processo era lento, sem metas bem definidas, e as centrais estavam sempre sobrecarregadas.

Figura 8: Logística de distribuição tradicional de argamassa.

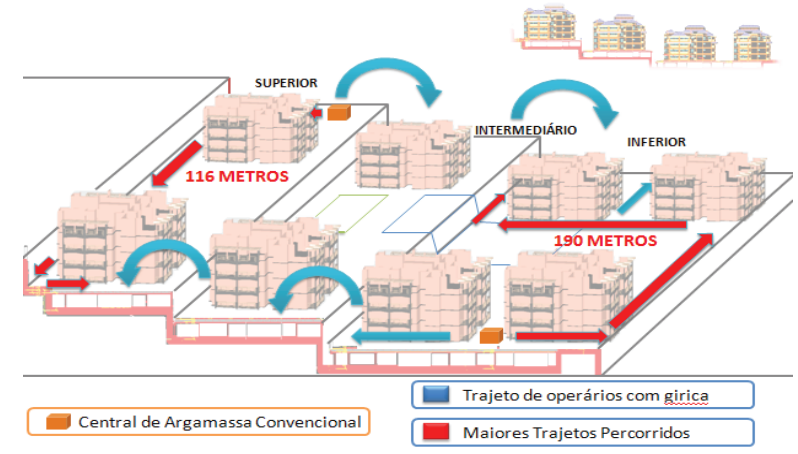

Trajeto de operários com girica

Maiores Trajetos Percorridos

Central de Argamassa Convencional

Fonte: Autor. 
A Empresa A fez, então, um investimento tecnológico no qual adquiriu dois sistemas de projeção de argamassa, compostos por: misturador; peneira vibratória; argamassa pré-fabricada; aditivo; mangueiras e bico de projeção. Para Sommerfeld (2016), esse sistema, aplicado na construção civil, exige qualificação de mão de obra, trazendo significativa redução de custos, além de qualidade ao processo construtivo. Nesse caso, foi contratada a consultoria de uma empresa especializada para consolidação e eficiência do sistema, a qual realizou treinamentos teóricos com gestores, encarregados e equipes de pedreiros da Empresa A (Figura 9a), além de práticos para essas equipes (Figura 9b). A Figura 9c mostra o posicionamento do equipamento junto a uma das centrais fixas do processo anterior.

Figura 9: Consultoria e aplicação de argamassa projetada.

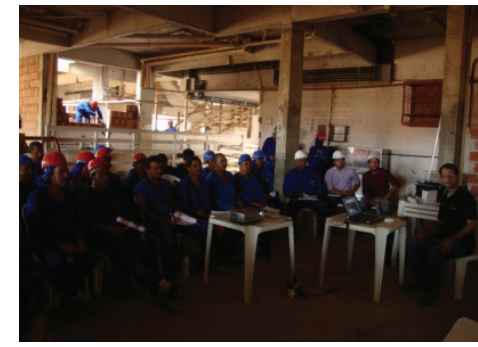

(a) Treinamento

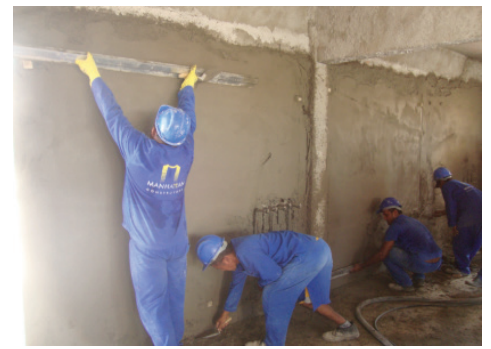

(b) Prática da projeção

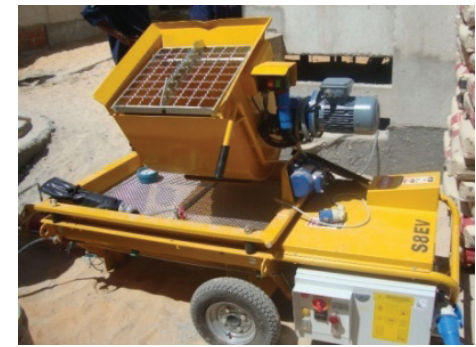

(c) Equipamento de projeção

Fonte: Autor.

Após um período de 15 dias de consultoria e treinamentos, iniciou-se de fato a estratégia de execução das projeções. A melhoria foi evidenciada através da mobilidade da central de projeção (posicionava-se o sistema de acordo com a necessidade) (Figura 10), do rápido poder de execução de revestimentos das fachadas, por conta da mecanização e do alcance das mangueiras, bem como da velocidade de projeção na parede devido ao jateamento de argamassa em vez da chapada manual do pedreiro. Os principais resultados da inovação do serviço foram dispostos na Tabela 5:

Figura 10: Nova logística de projeção de argamassa.

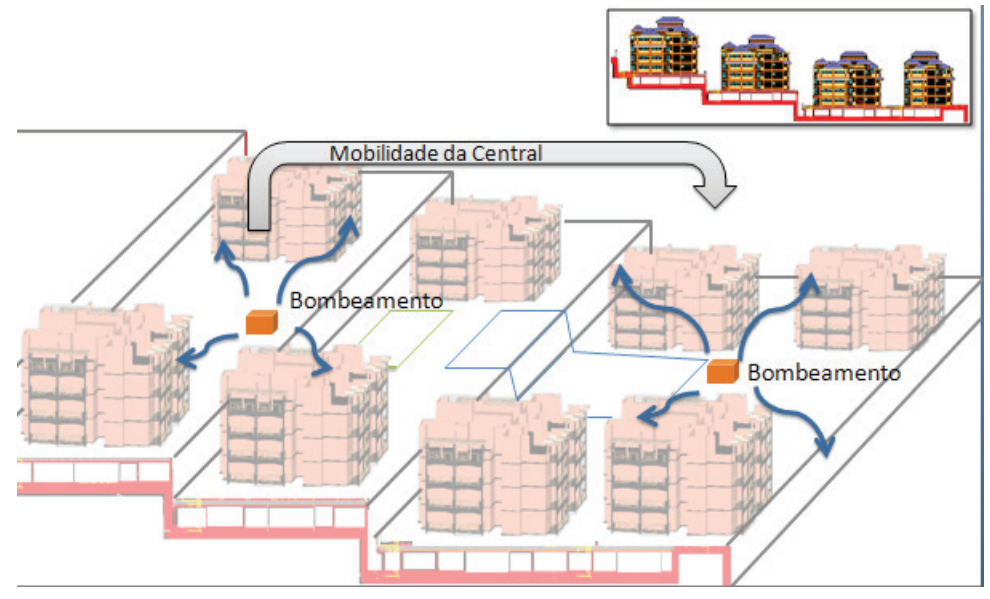

Fonte: Autor.
Lançamento Bombeado

Central Móvel de Projeção 
Tabela 5: Melhorias após a projeção de argamassa.

\begin{tabular}{|c|c|c|}
\hline Produtividade & & Ganho produtivo (\%) \\
\hline Execução manual chapisco: $25 \mathrm{~m}^{2} / \mathrm{h}$ (2 equipes) & $\begin{array}{l}\text { Projeção de chapisco: } 250 \quad \mathrm{~m}^{2} / \mathrm{h} \quad(2 \\
\text { equipes })\end{array}$ & $900 \%$ \\
\hline Execução manual de reboco: $15 \mathrm{~m}^{2} /$ pedreiro.dia & Projeção de reboco: $50 \mathrm{~m}^{2} /$ pedreiro.dia & $233,3 \%$ \\
\hline \multicolumn{3}{|l|}{ Logística e transporte } \\
\hline $\begin{array}{l}\text { Execução manual: central fixa; transporte } \\
\text { horizontal e vertical; equipes de serventes, giricas } \\
\text { e guinchos foguetes }\end{array}$ & $\begin{array}{l}\text { Projeção: bombeamento da central móvel } \\
\text { até o local de aplicação }\end{array}$ & \\
\hline Tempo (fabricação e execução) & & Ganho de tempo (\%) \\
\hline $\begin{array}{l}\text { Execução manual: média de } 17,5 \text { min. (por traço } \\
\text { no trecho): } \\
\text { Traço na betoneira: } 12 \text { minutos }(3 \text { minutos para } \\
\text { transpor padiolas de areia e arisco + cimento } \\
\text { na betoneira; } 6 \text { a } 8 \text { minutos virando o traço na } \\
\text { caçamba; } 1 \text { minuto para encher duas giricas com } \\
\text { o traço) } \\
\text { Percurso no pior trajeto (Figura } 8-190 \mathrm{~m}): \pm 1,26 \\
\text { minutos / girica (considerando a velocidade normal } \\
\text { do andar humano em trajeto plano estimada em } 9 \text { a } \\
12 \mathrm{~km} / \mathrm{h} \text { ou } 150 \mathrm{~m} / \mathrm{min} \text {. } \\
\text { Transporte vertical na torre: }+2 \text { minutos } \\
\text { (considerando baldes de } 18 \mathrm{~L} \text { subindo no foguete } \\
\end{array}$ & $\begin{array}{l}\text { Na projeção: } 5 \text { min. (aproximado) } \\
\text { Misturador: argamassa industrializada }+ \\
\text { aditivo + água: } \pm 5 \mathrm{~min} \\
\text { Percurso: bombeado (até } 340 \mathrm{l} / \mathrm{min} \text {.) } \\
\text { OBS: após posicionamento, montagem } \\
\text { das mangueiras e início de mistura, a } \\
\text { projeção fica praticamente instantânea. }\end{array}$ & $71,43 \%$ \\
\hline
\end{tabular}

Fonte: Autor.

\subsection{Aspectos da sustentabilidade no serviço de revestimento externo projetado}

Após a substituição do serviço de revestimento externo na maneira tradicional para a maneira mecanizada, observouse a significativa diminuição de fatores que remetiam a impactos ambientais, como poluição, geração de resíduos e impactos na ergonomia. Essa última, também se relaciona com sustentabilidade já que a performance humana é um fator crítico para a saúde coorporativa (GENAIDY et al., 2010; GENAIDY; SIQUEIRA et al., 2009). Os principais fatores minimizados foram:

- poluição: neste item, verifica-se o atendimento ao quesito ambiental, pois nos traços manuais, havia muita produção de poeira, ambientes sujos da central ao ponto de aplicação, barulhos, poluição visual. Na aplicação mecanizada, houve, pois, a diminuição do aspecto artesanal dos ambientes que remetia a estes fatores supracitados;

- geração de resíduos da construção: neste item, atende-se tanto ao quesito ambiental quanto ao econômico, pois os resíduos eram gerados em uma cadeia que iniciava na central, com o acúmulo de sacos de cimento, além de resíduos de agregados no entorno do local. Durante o transporte, desperdícios de argamassa que extravasa da girica em locais acidentados e durante a execução, desperdícios durante a aplicação por falha na aderência;

- impactos na ergonomia: neste item, houve melhoria no quesito social, sendo considerado pelos envolvidos como o de melhor performance sustentável. Na central de argamassa fixa, existia o esforço físico e muita exposição dos operários ao cimento. No trajeto, a equipe enfrentava longos trajetos de transporte e peso com giricas. Por fim, na execução, o pedreiro tinha que abaixar e levantar repetidas vezes, além de usar força para fixar argamassa na parede durante todo o dia. Com o novo processo, a argamassa é industrializada, lançada em um misturador mecânico adicionada de água e aditivo, onde a exposição e esforços são minimizados. O trajeto é bombeado e a execução é jateada por pressão. 


\section{Conclusão}

Foram evidenciadas melhorias ligadas às ferramentas Lean nos níveis estratégicos competitivos e operacionais da empresa, além da diminuição de impactos ambientais através da inovação tecnológica destas ferramentas e da projeção de argamassas. Verifica-se que empresas do setor da construção podem utilizar o Lean Construction e a sustentabilidade como uma vantagem competitiva, salientando a existência de similaridades entre as duas filosofias, tais como: a busca pela melhoria contínua, redução de desperdícios, transparência nos fluxos e valorização da qualidade.

Pode-se concluir que a aplicação da construção enxuta contribui para a maturidade socioambiental da empresa, assim como a adoção de procedimentos sustentáveis torna a obra mais lean. É necessária, porém, a conscientização e comprometimento de todos os funcionários envolvidos, valorizando ações como elaboração de uma estratégia eficaz, mão de obra capacitada, além de adaptações na cultura organizacional. Dessa forma, verificar-se-á se essas filosofias realmente irão suportar as suas estratégias competitivas, evitando-se o investimento de grandes esforços que acabem gerando futuras ferramentas obsoletas.

\section{Referências}

ALVES, T. C. L.; COSTA, G. S.; BARROS NETO, J. de P. Creating value in housing projects: the use of postoccupancy analysis to develop new projects. Construction Research Congress , p. 1105-1114, 2009.

BAE, Jin-Woo; KIM, Yong-Woo. Sustainable Value on Construction Project and Application of Lean Construction Methods. IGLC, Michigan, n. 15, p. 312-321, 2007.

BARROS NETO, J. de P. et al. Análise dos aspectos estratégicos da lean construction em construtoras cearenses. In: ENCONTRO NACION AL DE TECNOLOGIA DO AMBIENTE CONSTRUÍDO, 12., 2008, Fortaleza. Anais... . Fortaleza: ENTAC, 2008. p. 1-10. Disponível em: <http://www.infohab.org.br/entac2014/2008/artigos/A2027.pdf>. Acesso em: 15 abr. 2016.

BELLEN, H. Indicadores de sustentabilidade: uma análise comparativa. Rio de Janeiro: FGV, 2006.

BERNARDES, M. M. Desenvolvimento de um modelo de planejamento e controle da produção. 2001. 310f. Tese (Doutorado em Engenharia Civil) - Universidade Federal do Rio, Porto Alegre, 2001.

BIO, S. Sistemas de Informação: um enfoque gerencial. São Paulo: Atlas, 1985.

CAMPOS, I. B. et al. A relação entre a maturidade sustentável das empresas construtoras e a filosofia lean construction. In: ENCONTRO NACION AL DE TECNOLOGIA DO AMBIENTE CONSTRUÍDO, 14., 2012, Juiz de Fora. Anais... . Juiz de Fora: ENTAC, 2012. p. 2863-2871. Disponível em: <http://docplayer.com.br/6108328-A-relacao-entre-amaturidade-sustentavel-das-empresas-construtoras-e-a-filosofia-lean-construction.html>. Acesso em: 15 abr. 2016.

CORDEIRO, J. V. Alinhamento estratégico: estudos multicasos em empresas. Florianópolis: Universidade Federal de Santa Catarina, 2005.

CORRÊA, H. L.; GIANESI, I. G. N. Just in Time, MRP, OPT: um enfoque estratégico. São Paulo: Atlas, 1993.

COSTA, G. S., et al. Aplicação de um Modelo de Alinhamento Estratégico em Construtpras Cearenses. In: ENCONTRO NACIONAL DE ENGENHARIA DE PRODUCAO, 31., 2011, Belo Horizonte. Anais... . Belo Horizonte: ENEGEP, 2011. p 1-16. Disponível em: <http://www.abepro.org.br/biblioteca/enegep2011_tn_ stp_141_891_18941.pdf>. Acesso em: 3 fev. 2016.

FARIAS FIL HO, J. R., OLIVEIRA, J. T., GABRIELE, P. D. Proposta de ferramenta de avaliação preliminar do nível de maturidade da sustentabilidade empresarial no setor de construção civil. In: CONGRESSO NACIONAL DE EXCELÊNCIA EM GESTÃO, 5., 2009, Rio de Janeiro. Anais... . Rio de Janeiro: CNEG, 2009. p. 1-21. Disponível em: <http://www.inovarse.org/filebrowser/download/10183>. Acesso em: 26 fev. 2016.

FLYNN, B. B.; SAKAKIBARA, S.; SCHOERDER, R.G.; BATES, K.A; FLYNN, E. J. Empirical Research Methods in Operations Management. Journal of Operations Management, v. 9, n.2 , p. 250-278. 1990.

GENAIDY, A. M. et al. The Work Compatibility Improvement Framework: theory and application of improvement action and intervention strategies. Ergonomics, v. 52, n. 5, p. 524-59, maio. 2009.

GENAIDY, A. M. et al. The role of human at-work systems in business sustainability: perspectives based on expert and qualified production workers in a manufacturing enterprise. Ergonomics, v. 53, n. 4, p. 559-585, abr. 2010. 
A busca por um perfil competitivo e sustentável na estratégia organizacional de uma construtora cearense através do uso de ferramentas

GREENHALGH, G. R. Manufacturing strategy: formulation and implementation. Sydney: Addison-Wesley Publishing Company, 1991.

GUTIÉRREZ, A. Las ciudades de Gutiérrez. In: Revista Qué Pasa, Chile, Octubre 2007, p. 41-44. 2007.

HAYES, R. et al. Operations, strategy, and technology: pursuing the competitive edge. John Wiley \& Sons, 2005.

Hofacker, A. et al. Rapid Lean Construction-Quality Rating Model (LCR). Manchester: [s.n.], 2008. p. 241-250.

KAPLAN, R. S.; NORTON, D. P. Alinhamento: usando o balanced scorecard para criar sinergias corporativas. Rio de Janeiro: Elsevier, 2006.

KATHURIA, R.; JOSHI, M. P.; PORTH, Stephen J. Organizational alignment and performance: past, present and future. Management Decision, v. 45, n. 3, p. 503-517, 2007.

KOHLER N.; LÜTZKENDORF, T. Integrated life-cycle analysis. Building Research \& Information, n. 30 v. 5 , p. 338 348. 2002.

KOSKELA, L. Aplication of the new production philosophy to construction. Departament of Civil Engineering Stanford University, 1993, 75p.

MAO, X.; ZHANG, X. Construction process reengineering by integrating lean principles and computer simulation techniques. Journal of Construction Engineering and Management, ASCE, v. 134, n. 5, p. 371-381. 2008.

OGBORN, J. Constructivist Metaphors of Learning Science. Science \& Education, v. 6, p. 121-133, 1997.

OLIVEIRA, B. F. Um modelo de avaliação do grau de aplicação de ferramentas lean em empresas construtoras: o rapid lean Construction-quality rating model (LCR). Iberoamericana de Engenharia Industrial, Florianópolis, v. 2 , p. 156174. 2010.

PORTER, M. E. Estratégia competitiva: técnicas para análise de indústrias e da concorrência 9.ed. Rio de Janeiro: Campus, 1991.

SOMMERFELD, K. Produtividade em obras: um estudo do processo executivo de argamassa projetada em Belo Horizonte, Minas Gerais. Disponível em: $<$ http://revistapensar.com.br/engenharia/pasta_upload/artigos/a119.pdf $>$. Acesso em 19 abr. 2016.

SOUSA, D. P. et al. Uma metodologia de implantação do sistema Toyota de produção em uma empresa de construção de edifícios a partir do suporte tecnológico do Programa de Inovação da Construção Civil do Ceará (INOVACON-CE). In: SIMPÓSIO BRASILEIRO DE GESTÃO E ECONOMIA DA CONSTRUÇÃO, 4.,2005, Porto Alegre. Anais... Porto Alegre, 2005. p. 1-10.

SUN, H.; HONG, C. The alignment between manufacturing and business strategies: its. Technovation: [s.1.], v. 22, $\mathrm{n}$. 11, p. 699-705, 2002.

WOMACK, J. P.; JONES, D.T. A mentalidade enxuta nas empresas: elimine o desperdício e crie riqueza. São Paulo: Campus, 1998.

YANG, M. G.; HONG, P.; MODI, S. B. Impact of lean manufacturing and environmental management on business performance: An empirical study of manufacturing firms. International Journal of Production Economics, Toledo, v. 129, n. 2, 2011.

YIN, R. K. Case study research: design and methods. 3. ed.. London: Sage publications, 2003. 94 p. Disponível em: $<\mathrm{http} / / / \mathrm{s} 3$.amazonaws.com/academia.edu.documents/39401202/Yin_-_Case_study_research_3rd.pdf?AWSAccessKey $\mathrm{Id}=$ AKIAJ56TQJRTWSMTNPEA\&Expires $=1467145500 \&$ Signature $=$ KCeIacKnCmrgT\%2BJIgzADD\%2FGUJjg\%3D \&response-content-disposition=inline\%3B\%20filename\%3DCase_Study_Research.pdf $>$ Acesso em: 15 abr. 2016. 
Sobre os autores

\section{Pedro Rodolfo Freitas de Matos}

Graduação em Engenheiro Civil, Universidade Federal do Ceará - UFC. Pós-graduado em Gerenciamento de Obras da Construção Civil, Universidade de Fortaleza- UNIFOR.

\section{Bruno Mota}

Graduado em Engenharia Civil pela Universidade Federal do Ceará (UFC), Especialista com MBA em Gerenciamento de Projetos pela Fundação Getúlio Vargas (FGV) e Mestrando em Engenharia Civil pelo NORIE da Universidade Federal do Rio Grande do Sul (UFRGS; Professor dos cursos de MBA pelo INBEC e pela UNIFOR; Diretor técnico da SIPPRO (Soluções de Planejamento da Produção), empresa de consultoria, com projetos em 4 estados brasileiros, nas áreas de gestão de obras, orçamentos, planejamento e controle da produção integrados às tecnologias da informação e ao BIM.. 